\title{
Correction to: Indirect positive effects of agricultural modernization on the abundance of Japanese tree frog tadpoles in rice fields through the release from predators
}

\author{
Naoki Katayama - Tetsuo Goto - Fumihiro Narushima - Tatsuya Amano • \\ Hiromi Kobori · Tadashi Miyashita
}

Published online: 21 October 2021

(C) Springer Nature B.V. 2021

Correction to: Aquat Ecol (2013) 47:225-234

https://doi.org/10.1007/s10452-013-9437-0

After the publication of the article, we became aware of the fact that the alien pond loach Misgurnus dabryanus, which is morphologically similar to the native dojo loach M. anguillicaudatus, also inhabits in our study region (Ibaraki Prefecture). Thus, the negative effect of loach on tadpoles in rice fields (Fig. 3) may be caused by both of these Cobitidae

The original article can be found online at https:// doi.org/10.1007/s10452-013-9437-0.

\footnotetext{
N. Katayama ( $\square)$

Biodiversity Division, National Institute for Agro-

Environmental Sciences, 3-1-3 Kannondai, Tsukuba-shi,

Ibaraki 305-8604, Japan

e-mail: katayama6@affrc.go.jp

T. Goto $\cdot$ F. Narushima $\cdot$ H. Kobori

Faculty of Environmental and Information Studies, Tokyo

City University, 3-3-1 Ushikubo-nishi, Tsuzuki-ku,

Yokohama 224-0015, Japan

T. Amano

Conservation Science Group, Department of Zoology,

University of Cambridge, Downing Street,

Cambridge CB2 3EJ, UK

T. Miyashita

Laboratory of Biodiversity Science, School of

Agricultural and Life Sciences, University of Tokyo, 1-1-

1 Yayoi, Bunkyo-ku, Tokyo 113-8657, Japan
}

loaches. Besides, it is possible that the loach individuals used in our laboratory experiment, which were from a commercial fish market, were not the dojo loach. These facts do not change our conclusion that biological factors can be important for the abundance and spatial distribution of frogs in rice fields, but a greater understanding of the impact of alien fish species on native animals in rice ecosystems is necessary.

Publisher's Note Springer Nature remains neutral with regard to jurisdictional claims in published maps and institutional affiliations. 